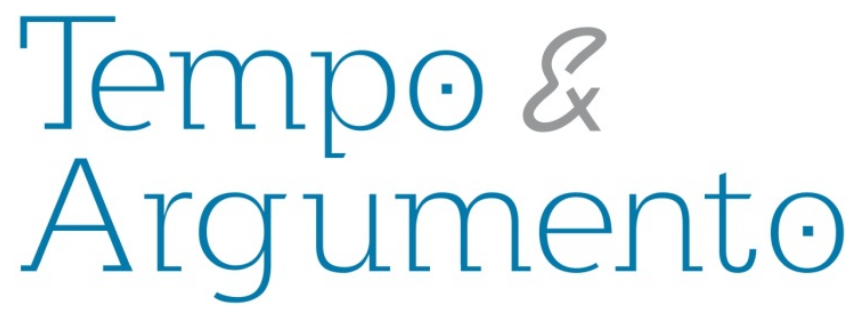

\title{
Brasiliana \& História Geral da Civilização Brasileira: escrita da história, disputas editoriais e processos de especialização acadêmica (1956-1972)
}

\begin{abstract}
Resumo
O presente artigo analisa aspectos da coleção Brasiliana, sob a direção de Américo Jacobina Lacombe, e da História Geral da Civilização Brasileira (HGCB), na época em que foi coordenada por Sérgio Buarque de Holanda. O estudo abrange o período compreendido entre os anos de 1956 e 1972. Contempla fontes bibliográficas e documentais, particularmente dos arquivos pessoais dos autores mencionados, quando referentes aos empreendimentos editoriais que organizaram. $O$ objetivo principal é refletir sobre a institucionalização e especialização acadêmica da área de História no Brasil, evidenciada por meio dos processos de organização das coleções.
\end{abstract}

Palavras-chave: Brasiliana. Américo Jacobina Lacombe. HGCB. Sérgio Buarque de Holanda. Coleções

\section{Giselle Martins Venâncio Doutora em História.}

Professora da Universidade Federal Fluminense. giselle@historia.uff.br

\section{André Carlos Furtado}

Mestrando do Programa de Pós-

graduação em História da Universidade Federal Fluminense. afurtado@id.uff.br

\section{Para citar este artigo:}

VENÂNCIO, Giselle Martins; FURTADO, André Carlos. Brasiliana \& História Geral da Civilização Brasileira: escrita da História, disputas editoriais e processos de especialização acadêmica (19561972). Revista Tempo e Argumento, Florianópolis, v. 5, n.9, jan./jun. 2013. p. 05 - 23. 
Brasiliana and história geral da civilização brasileira: History, editorial disputes and academic specialization processes (1956-1972)

\begin{abstract}
This article examines aspects of the Brasiliana collection, when it was under the direction of Americo Jacobina Lacombe, and História Geral da Civilização Brasileira(HGCB), which at the time was coordinated by Sérgio Buarque de Holanda. The study covers the period between the years of 1956 and 1972 and includes bibliographic and documentary sources, particularly from personal files of the mentioned authors when referring to the publishing ventures they organized. Its primary purpose is to reflect on the institutionalization and academic specialization of the History area in Brazil, shown through the process of organization of such collections.
\end{abstract}

Keywords: Brasiliana. Américo Jacobina Lacombe. HGCB. Sérgio Buarque de Holanda. Collections. 
Este texto pretende analisar dois projetos editoriais desenvolvidos ao longo da segunda metade do século XX no Brasil: a Brasiliana, publicada pela Companhia Editora Nacional, e a História Geral da Civilização Brasileira (HGCB), editada pela Difusão Europeia do Livro. Para tanto, as fontes de que se pretende lançar mão dizem respeito não só aos livros dos referidos empreendimentos - que permitem reconstituir partes significativas do conjunto de impressos publicados no período -, mas também a documentos mais diretamente ligados a seus responsáveis, como correspondências, planos de trabalho e contratos de publicação.

Tais escolhas se atrelam ao entendimento que compreende esse tipo de fonte como parte constitutiva do complexo de forças apreciadas como cultura escrita (CHARTIER, 1994), uma vez que, dentre outras questões, busca vislumbrar disputas, usos e interpretações. Além disso, possibilita incursões na história do livro, com destaque para as referidas propostas editoriais, pois estas representam os esforços de estabelecimento da especialização acadêmica empreendidos entre os anos 50 e 70 no Brasil, cuja "energia social” (GALLAGHER; GREENBLATT, 2005, p. 23) confirma a assertiva que vê a criação de coleções vinculada ao ritmo das condições políticas, econômicas e culturais (OLIVERO, 1999) de determinada época e lugar. Assim, parte-se da ideia de que as coleções Brasiliana e HGCB correspondem a momentos distintos do processo de especialização dos saberes no Brasil deste período, o que se evidencia em seus projetos editoriais.

A primeira coleção, a Brasiliana, foi criada em 1931 pela Companhia Editora Nacional, então de propriedade de Octalles Marcondes Ferreira. Esta coleção se tornou, ao longo dos anos em que foi publicada, entre 1931 e 1993, um privilegiado espaço de difusão da produção intelectual sobre o Brasil, constituindo-se em uma biblioteca real e metafórica sobre o País (SORÁ, 2010). O conjunto de livros organizou-se em duas fases distintas: uma primeira, na qual foi dirigida por Fernando de Azevedo ${ }^{1}$ e, uma segunda, a partir de 1956 (até 1993), quando foi publicada sob a coordenação de Américo Jacobina

\footnotetext{
${ }^{1}$ Sobre a Brasiliana sob a direção de Fernando de Azevedo, ver: DUTRA, 2006.
} 
Lacombe $^{2}$. Neste texto será tratada apenas a segunda fase, durante a qual a Brasiliana foi dirigida por Américo Jacobina Lacombe.

A outra coleção, HGCB, foi editada pela Difusão Europeia do Livro, e também contou com dois momentos distintos: um primeiro, sob a direção de Sérgio Buarque de Holanda $^{3}$, e um segundo, sob a coordenação de Boris Fausto ${ }^{4}$, ao longo do período que vai de 1960 a 1984, com uma soma total de 11 volumes. Apesar de se constituir com uma gama variada de colaboradores das mais diversas instituições científicas e/ou de fomento à cultura, como a Faculdade de Filosofia de Marília, o Museu Paulista e a Casa Rui Barbosa, durante o período em que Sérgio Buarque esteve à frente da coleção houve um forte predomínio de autores ligados à Universidade de São Paulo (USP). Dentre outras questões, por conta desta particularidade, neste texto será dada prioridade ao período da HGCB, compreendido entre 1960 e 1972, em que esteve sob seu domínio.

\footnotetext{
${ }^{2}$ Américo Jacobina Lacombe nasceu no Rio de Janeiro em 1909 e morreu nesta mesma cidade em abril de 1993. Quando jovem, estudou no Curso Jacobina, de propriedade de sua família, e, posteriormente, se transferiu para o colégio Arnaldo, em Belo Horizonte. Em 1927, iniciou o bacharelado na faculdade de Direito, formando-se em 1931. Neste mesmo ano, tornou-se secretário do Conselho Nacional de Educação, onde permaneceu até 1939, ano em que foi nomeado diretor da Casa de Rui Barbosa. Dirigiu esta instituição por 54 anos, afastando-se apenas em dois momentos: quando foi secretário de Educação e Cultura do antigo Distrito Federal, entre 1959 e 1960, na administração do prefeito Freire Alvim, e entre 1962 e 1963, quando presidiu a Casa do Brasil, em Paris. Lacombe foi ainda professor de História em vários colégios do Rio de Janeiro e na Pontifícia Universidade Católica e professor de História do ensino de História do Instituto Rio Branco (Itamarati), além de ter sido presidente do Instituto Histórico e Geográfico Brasileiro (IHGB) e, a partir de 1951, ter integrado a Comissão de textos de História do Brasil do Ministério das Relações Exteriores. Sobre a biografia de Lacombe, ver: SENNA, 1996; e MAGALHÃES, 1996.
}

${ }^{3}$ Sérgio Buarque de Holanda nasceu em São Paulo em 1902 e morreu nesta mesma capital, em 1982. Fez o ginásio no Colégio S. Bento e no Arquidiocesano. Em 1921, transferiu-se para o Rio de Janeiro, onde se matriculou na faculdade de Direito, cuja formação mal chegou a exercer e cujo diploma só retiraria décadas depois, em 1957. Ainda nos anos 20, envolveu-se nas discussões do movimento modernista, quando também iniciou suas colaborações na imprensa, que manteria, apesar de oscilatórias, por praticamente toda a sua vida, sobretudo em periódicos do eixo Rio-São Paulo. Parte em 1929 para a Alemanha, como enviado especial d'O Jornal, então de propriedade do magnata das comunicações, Assis Chateaubriand. De volta à terra natal, retorna às redações e, em 1936, publica seu primeiro texto, Raízes do Brasil, como o livro inicial da coleção intitulada Documentos Brasileiros, da editora José Olympio. Em 1939, começa a trabalhar no Instituto Nacional do Livro - INL; em 1944, assume a Divisão de Consultas da Biblioteca Nacional e, em 1946, o Museu Paulista. Buarque de Holanda também lecionou como professor convidado em inúmeras instituições acadêmicas, a exemplo da Universidade de Roma (1952-1954), e, a partir de 1958, assume a cátedra História da Civilização Brasileira da USP, na qual permanece até a aposentadoria, em 1969. Sobre a biografia de Holanda, ver: NOGUEIRA et al., 1988; HOLANDA, 2002; e NOVAIS, 2010.

${ }^{4}$ Doutor em História desde 1968 pela USP. Sobre a HGCB, sob a direção de Boris Fausto, ver: FAUSTO, 1988; GOMES, 2008; e FAUSTO, 2010. 
Investigar as coleções Brasiliana e HGCB é, em grande medida, revisar a história intelectual do País, mais especificamente o processo de especialização e institucionalização da História - lócus privilegiado da discussão sobre o Brasil - ao longo dos anos compreendidos entre 1956 e 1972. É também identificar o curso por meio do qual os impressos se investiram da condição de legitimação dos processos de monumentalização das obras e textos neles publicados, questão que envolve não apenas os aspectos relacionados aos autores dos textos, mas também os editores e críticos, entre outros agentes que exerceram variadas funções de mediadores ${ }^{5}$, visto que os artefatos culturais sempre "existem no tempo e estão ligados a conflitos, negociações e apropriações pessoais e institucionais" (GREENBLATT, 1991, p. 244).

As coleções publicadas no período aqui privilegiado condensavam os primeiros resultados acadêmicos das instituições criadas no Brasil nos anos $30^{6}$, especialmente as estabelecidas em São Paulo e no Rio de Janeiro, isto é, a USP ${ }^{7}$ e a Faculdade Nacional de Filosofia (FNFi) da Universidade do Brasil $^{8}$. Ambas as instituições integraram o processo de profissionalização das Ciências Sociais e Humanas no País e contribuíram para o debate sobre a renovação dos cânones científicos, em especial os historiográficos, em curso nos anos 50 e 60.

Além destas instituições, é importante destacar o Instituto Superior de Estudos Brasileiros (Iseb), criado em 1955, porque este é também um dos mais concretos resultados deste processo de institucionalização. Vinculado ao Ministério da Educação e localizado no Rio de Janeiro, o Iseb foi, ao lado da USP e da FNFi, durante a segunda metade dos anos 50, uma das instituições mais destacadas no espaço intelectual brasileiro.

Dessa forma, pode-se considerar que a segunda metade do século XX marca o

\footnotetext{
${ }^{5}$ Sobre mediação cultural, ver: HEINICH, 2008.

${ }^{6}$ Os autores que abordam a questão da história das Ciências Sociais no Brasil são unânimes em identificar o período entre 1946 e 1964 como de consolidação dos estudos produzidos na USP e na Escola Livre de Sociologia e Política, bem como na FNFi, instituições criadas nos anos 30. Ver: MICELI, 1989; VILHENA, 1997; e VILAS BOAS, 2007.

7 Sobre a criação dos cursos de Geografia e História na USP, ver, entre outros: ROIZ, 2007.

${ }^{8}$ Sobre a FNFi, ver: FERREIRA, 2012.
} 
momento dos primeiros frutos da reconfiguração do campo intelectual no Brasil, caracterizado pelo processo de institucionalização em curso desde meados dos anos 30, e que tanto a Brasiliana quanto a HGCB evidenciam este processo de especialização dos saberes, particularmente da História. Como já afirmou Isabelle Olivero, a emergência de empreendimentos editoriais no formato de coleções está intimamente ligada a modificações nos espaços de produção das narrativas científicas, educacionais e literárias de um país, pois estas contribuem para a produção de novos livros, que buscam responder a novos objetivos e necessidades (OLIVERO, 1999, p. 31).

Assim, parte-se da ideia de que estas coleções correspondem a diferentes momentos do processo de especialização dos saberes no Brasil deste período, o que se evidencia em suas distintas propostas editoriais.

No que se refere às características formais, a Brasiliana é uma coleção cujos volumes são, normalmente, de autoria única. São textos monográficos, que contemplam aspectos específicos sobre o Brasil ou seus principais personagens. O objetivo de seus editores, desde o início, era que a coleção condensasse, "de um só golpe de vista, [...] toda a cultura nacional" (SORÁ, 2010) e se tornasse uma síntese do País, destinada a um leitor experiente, já iniciado nos estudos sobre o Brasil ${ }^{9}$.

Quanto à autoria dos textos, embora haja uma forte presença dos intelectuais associados às universidades criadas desde os anos 30, é possível perceber, no espaço de tensão estabelecido no interior da Brasiliana, também a presença de grupos situados fora do ambiente acadêmico, como, por exemplo, os que tinham como espaços privilegiados de atuação o Instituto Histórico e Geográfico Brasileiro (IHGB), os institutos históricos regionais e as academias de letras.

Américo Jacobina Lacombe tornou-se diretor da Brasiliana em 1956, notícia amplamente divulgada pelos jornais da época ${ }^{10}$. Nos 37 anos em que a coleção esteve sob

\footnotetext{
9 Em seu estudo sobre a Biblioteca Pedagógica Brasileira (BPB), Maria Rita Toledo acentua este aspecto. Diz ela: "A orientação do plano editorial articula e arregimenta todos os públicos, porque pretende fornecer livros para todas as idades, dos leitores iniciantes àqueles habilitados a compreender a sistematização dos estudos brasileiros contida na Brasiliana, atendendo a política de formação do leitor brasileiro"(TOLEDO, 2010, p. 152).

${ }^{10} \mathrm{O}$ arquivo de Lacombe guarda um número significativo de recortes de jornais de vários locais do Brasil
} 
sua direção, foram publicados 123 títulos, incluindo os 26 da série Brasiliana Grande Formato e dois da série especial. No período inicial da direção de Américo Jacobina Lacombe, houve um significativo incremento na produção da coleção. Entre 1957 e 1961, foram publicados 22 novos títulos, uma média de cinco por ano, o que evidencia, certamente, a boa fase da indústria editorial brasileira, garantida, entre outros fatores, por uma legislação favorável à ampliação do mercado editorial nacional ${ }^{11}$.

Os novos títulos da coleção eram, em sua maioria, estudos inéditos sobre a realidade brasileira, produzidos principalmente nas faculdades de Ciências Sociais organizadas no período, o que evidencia um resultado concreto do processo de reconfiguração do campo intelectual, marcado por ações de institucionalização e especialização, em curso desde os anos 30, e que havia reorganizado a posição de seus agentes, (re)definindo novos cânones e reposicionando autores referenciais.

No que se refere, especificamente, aos textos que podem ser caracterizados como de escrita da história, no período entre 1956 e 1961 a Brasiliana publicou, preferencialmente, autores que atuavam fora das universidades. Este é o caso, por exemplo, dos livros O Amazonas e sua História (1957), de Anísio Jobim e O ouro das Gerais e a civilização da Capitania (1957), de João Dornas Filho. No entanto, neste período, a Brasiliana publicou também Os holandeses no Brasil, 1624-1654, de Charles Boxer (1961), texto representativo de uma escrita de história mais especializada e institucionalizada.

As escolhas dos títulos a serem publicados na Brasiliana revelam, sem dúvida, as disputas no interior da coleção. Assim, embora haja publicações de textos de professores das universidades brasileiras, particularmente de antropólogos e cientistas sociais,

que registram esta notícia.

${ }^{11}$ Glaucia Vilas Boas identifica o mesmo incremento da produção editorial na área de Ciências Sociais no período compreendido entre 1954 e 1959. No prefácio ao livro de Villas Boas, José Murilo de Carvalho argumenta que "o período de JK representou na produção de livros de ciências sociais o mesmo que significou em outros campos, isto é, um momento de explosão de criatividade" (CARVALHO, 2007, p. 17). No entanto, neste texto, consideramos que esse incremento se deu especialmente por uma legislação favorável economicamente à publicação de livros no Brasil neste período, ilustrada pelo decreto n. 25.442, de 3 de setembro de 1948, - posteriormente alterado para as leis 842 , de 4 de outubro de 1949 e 2.145, de 19 de setembro de 1953 -, que taxava mais rigorosamente os livros impressos e editados fora do Brasil, favorecendo a ampliação do mercado editorial nacional. 

coleção. Américo Jacobina Lacombe foi convidado para ocupar o cargo de presidente da Maison du Brésil, em Paris, casa fundada com o objetivo de abrigar os estudantes brasileiros que se dirigiam à capital francesa. A saída de Lacombe coincidiu com um período de desaceleração do processo de publicação da coleção. No ano de 1962, nenhum título foi publicado; em 1963, apenas dois e, em 1964, cinco. O declínio do ritmo de publicações é, neste período, simultâneo às dificuldades enfrentadas pela indústria editorial no País, porque nos governos de Janio Quadros e João Goulart foi revogada a legislação, criada nos anos 50, que dificultava a importação de livros e estabelecidas novas leis fiscais que tornaram mais cara a importação de papel, ainda bastante necessária à indústria brasileira. É seguro supor que este período tenha marcado também uma diminuição do prestígio de Jacobina Lacombe no interior da Brasiliana e da Companhia Editora Nacional.

Ao longo destes anos, a situação realmente foi se tornando mais grave para o mercado editorial e livreiro e, particularmente, para a Brasiliana. Por este motivo, seus editores, cada vez mais, buscavam mediadores que pudessem auxiliar a retomada das vendas e garantir a continuidade da coleção. Era preciso colocar a Brasiliana, novamente, no lugar prestigiado que ela sempre havia ocupado no mercado editorial brasileiro. Mas era também importante editar novos títulos, principalmente daqueles autores que, experimentados na primeira fase da coleção, resultaram em sucesso. Os projetos de reedição e a ação mais agressiva junto aos críticos, articuladas por Lacombe e Thomas Aquino, sob a direção de Octalles Ferreira, foram as estratégias executadas, o que parece ter dado bom resultado, pois, a partir de 1965, a Brasiliana entrou numa nova fase de expansão. Nesta, a publicação dos livros foi muitas vezes promovida por coedições com o Instituto Nacional do Livro (INL) ou com editoras universitárias, como a da USP.

A retomada da expansão da Brasiliana coincidiu com a volta de Lacombe ao Brasil

\footnotetext{
${ }^{12}$ Sobre os marxistas nas brasilianas, ver: FRANZINI, 2011.
} 
e com sua ação mais direta sobre a organização da coleção. Este é o período de maior ação de Jacobina Lacombe no projeto editorial: ele atua não apenas como diretor, mas também como tradutor, prefaciador e apresentador dos volumes. Nesta fase, muito produtiva, porém bastante heterogênea em termos da seleção dos títulos do catálogo, destacam-se, na coleção, livros como a reedição de Os dois brasis, de Jacques Lambert; A Idade de Ouro do Brasil; dores de crescimento de uma sociedade colonial, de Charles Boxer, e Visão do paraíso, de Sérgio Buarque de Holanda.

No entanto, a morte de Octalles Marcondes Ferreira, em 1973, bem como acontecimentos da história política do fim dos anos 60 e da trajetória de Américo Jacobina Lacombe ${ }^{13}$ marcariam os primeiros tempos da coleção nos anos 70. Com a saída de Octalles, e diante da impossibilidade de negociação com a editora José Olympio, que, a princípio, se havia interessado pela compra da Nacional, a editora passou às mãos do BNDE e foi indicado, para sua direção, um profissional de carreira deste banco, Ezio Távora, indivíduo que, ao que tudo indica, não possuía nenhuma trajetória no mercado editorial e livreiro ${ }^{14}$. Apesar dos novos tempos e da nova organização institucional, Lacombe manteve-se na direção da coleção até 1993, momento de sua morte e também de finalização deste projeto editorial.

A segunda coleção em análise, a HGCB, pode ser incluída nos esforços de ampliação dos projetos de tentativa de compactação dos saberes do mundo, produzidos pela Difusão Europeia do Livro. Isso porque sua impressão foi iniciada após as traduções do francês para o português ${ }^{15}$, e publicação no Brasil das coleções História Geral das

\footnotetext{
${ }^{13}$ Nos anos 60, Américo Jacobina Lacombe envolveu-se em uma importante polêmica política. Ao produzir um parecer sobre a coleção História Nova do Brasil, que se organizou sob a direção de Nelson Werneck Sodré, Jacobina Lacombe foi acusado de promover a cassação dos autores da coleção. Sobre esta polêmica, ver: LOURENÇO, 2008.

${ }^{14}$ Embora não se tenha encontrado nenhuma relação entre Ezio Távora e o mercado editorial, é possível supor que ele possuísse algum prestígio no campo intelectual, pois Maria Arminda Arruda o identifica na lista de autores publicados na Revista Brasileira de Ciências Sociais, entre outros intelectuais da USP, do Iseb e de instituições públicas governamentais. Ver: ARRUDA, 1989.

${ }^{15}$ Vale frisar que a tradução, por exemplo, da coleção História Geral das Civilizações foi realizada por Pedro Moacyr Campos, então professor ajunto da Faculdade de Filosofia, Ciências e Letras (FFCL) da Universidade de São Paulo (USP), que, posteriormente, deu assistência a Sérgio Buarque de Holanda na coordenação da HGCB.
} 
desta "iniciativa benemérita [...] [que], com o mesmo formato, [...] [criou] uma série especial dedicada à história do Brasil ou, segundo o plano anteriormente estabelecido, à história da 'civilização' brasileira” (HOLANDA, 1960, p. 7). Portanto, as temáticas que seriam privilegiadas reportavam especificamente à História do Brasil, mas com um recorte temporal marcado pela chegada dos europeus ao continente, circunstância que recentemente foi nomeada, por Temístocles Cezar, como "cronologia civilizacional" (CEZAR, 2013).

Tal aspecto difere da coleção Brasiliana, pois, nesta última, as publicações não se circunscreviam a temáticas que dissessem respeito somente à História; seu projeto editorial manteve o plano de reunir um saber enciclopédico nas mais variadas áreas de conhecimento, constituindo-se por meio da reedição de obras clássicas, ou raras, sobre temas nacionais, além de traduções ou publicações de novos títulos atentos aos problemas do Brasil (DUTRA, 2006). Portanto, a Brasiliana não pretendia manter suas obras restritas aos temas de História, como foi o caso da HGCB, cujo esforço se direcionou neste sentido.

Desta forma, a HGCB representava a ampliação dos projetos da Difusão Europeia do Livro, como a caracterizou Buarque de Holanda na Introdução geral da coleção, por ele coordenada entre 1960 e 1972. Como a História Geral das Civilizações já estava concluída com 17 volumes, publicados entre 1955 e 1958, e a publicação no Brasil da História Geral das Ciências, também da Difusão Europeia do Livro, se encontrava em curso ${ }^{16}$, pode-se caracterizar a HGCB como a versão tropical dos empenhos de extensões transoceânicas da editora, atenta à ampliação do mercado consumidor, fim último de toda transação desta natureza.

Quanto à organização da HGCB, sua estrutura impressa foi pensada de forma a dividir a coleção em dois grandes grupos: os "Tomos" e os "Volumes", que tratavam das

\footnotetext{
${ }^{16}$ A publicação no Brasil da História Geral das Ciências se finalizou em 1967, com um total de 14 volumes.
} 
dimensões da Colônia, do Império e da República brasileira. Assim, dentro do período coordenado por Sérgio Buarque de Holanda, foram publicados os Tomos I e II: o primeiro, intitulado A Época Colonial, foi desdobrado nos Volumes Do descobrimento à expansão territorial \& Administração, economia, sociedade, ambos publicados em 1960. Já o segundo Tomo, O Brasil Monárquico, foi dividido em O processo de emancipação (1962), Dispersão e unidade (1964), Reações e transações (1967), Declínio e queda do Império (1971) e Do Império à República (1972) ${ }^{17}$.

No que se refere à autoria dos textos, a HGCB se caracteriza pela estruturação em forma de coletânea. Os capítulos que compõem seus volumes buscam tratar, especificamente, de questões da História do Brasil, organizadas cronologicamente, obedecendo às eras nacionais (Colônia, Império e República) e marcadas por um recorte temporal que toma por base o ano de 1500, persistente e firmado na cultura histórica ${ }^{18}$ do Brasil até os dias de hoje.

É importante destacar que os Tomos A Época Colonial e O Brasil Monárquico contaram com aval acadêmico concedido pela USP e, em particular, "sob os auspícios" (HOLANDA, 1960, p. 5) da Faculdade de Filosofia, Ciências e Letras (FFCL), mais tarde denominada Faculdade de Filosofia, Letras e Ciências Humanas (FFLCH), em virtude das mudanças no ensino superior, empreendidas e exigidas pelas reformas do governo autoritário (SÃO PAULO, 1969). Este apoio formal, no entanto, se estende somente até 1972, quando é impresso o último volume sob a coordenação de Sérgio Buarque de Holanda na coleção. Talvez esta circunstância explique parte da constatação de que, quando se analisa o período em que ele coordenou o empreendimento, das 132 colaborações publicadas, 82 (62,12\%) contêm a marca da USP na identificação institucional das autorias, independente de um(a) colaborador(a) se responsabilizar por mais de um

\footnotetext{
${ }^{17}$ Sob a coordenação de Boris Fausto, o Tomo III (O Brasil Republicano), por sua vez, contou com os Volumes Estrutura de poder e economia (1889-1930), publicado em 1975; Sociedade e instituições (1889-1930), em 1977; Sociedade e política (1930-1964), em 1981, e Economia e cultura (1930-1964), impresso em 1984, quando a coleção chega ao fim. A cronologia limite da História do Brasil Republicano, implementado pela HGCB, busca não ultrapassar muito o golpe civil-militar de 1964, embora Fausto mencione, em entrevista, que alguns colaboradores "transgrediram" - a palavra é do organizador - o recorte temporal, com avanço sobre temáticas relativas aos anos de 1970. Ver: FAUSTO, 1988.

${ }^{18}$ Sobre este conceito, ver, dentre outros: LE GOFF, 1992.
} 
texto ou de este ser escrito em coautoria ${ }^{19}$. Deve-se ainda destacar o predomínio do próprio organizador inicial da série, com um total de 34 textos. Além da Introdução geral, Sérgio Buarque escreveu 33 capítulos (sendo apenas dois em coautoria, com Pedro Moacyr Campos e com Olga Pantaleão), dos quais 19 constituem o $7^{\circ}$ volume do Tomo II, a saber, a obra completa Do Império à República.

Além da questão do predomínio da USP, há de se atentar também para o fato de que 25 das colaborações $(13,22 \%)$ de toda a coleção são de autorias sem vínculo institucional declarado e que poderiam ser de um mesmo colaborador, então substituído por identificações como: historiador, historiador e médico, historiador e economista, professor liceal, crítico de música popular e até de general do Exército Nacional. Deste total de 25 colaborações, 24 (12,69\%) delas fazem parte do momento correspondente ao período coordenado por Sérgio Buarque (1960-1972), situação que reporta às fragilidades, ainda nos anos 60, do processo de especialização institucional da História no Brasil.

A propósito deste aspecto, vale registrar que a correspondência trocada entre colaboradores, bem como entre estes e o organizador da HGCB, revela parte do movimento de composição e discussão das temáticas a serem desenvolvidas na coleção, da mesma forma que permite vislumbrar algumas contestações ao projeto editorial da HGCB, que traduzem fragilidades de estruturação institucional, então em curso, na área de História no Brasil.

A título de exemplo, cabe mencionar o debate entre Sérgio Buarque de Holanda e o historiador amazonense Arthur Cezar Ferreira Reis ${ }^{20}$, cujos capítulos integravam o conjunto das 24 colaborações sem origem institucional registrada junto aos textos publicados na HGCB. Em resposta à carta enviada por Ferreira Reis, logo após a

\footnotetext{
${ }^{19}$ Somente no momento em que Boris Fausto assume a coordenação da HGCB é que o quadro exposto se modifica. Isso porque, nas publicações de 1975 a 1984, das 57 colaborações que aparecem registradas nos volumes finais da coleção (Tomo III, O Brasil Republicano), 18 (31,57\%) contêm a identificação da USP junto das autorias. Portanto, este levantamento possibilita inferir que, apesar de permanecer bem representada, quando Buarque de Holanda deixa a organização da coleção, a instituição paulista deixa de predominar sobre o conjunto de instâncias da produção de conhecimento que figuram na composição dos textos da HGCB. O projeto editorial, aliás, também deixa de contar formalmente com o aval acadêmico da USP, como ocorrera nos tomos coordenados por Sérgio Buarque de Holanda.

${ }^{20}$ Depois de Sérgio Buarque de Holanda, Arthur Cezar Ferreira Reis foi o autor mais assíduo da coleção HGCB, na fase 1960-1972, com um total de 10 capítulos.
} 
publicação do volume intitulado Do Império à República, em 1972 - então sétimo volume da HGCB -, no qual ele se dizia “"pasmo' com a total ausência de referência, por mais reduzida que fosse, à Amazônia", como na questão dos processos migratórios, Buarque de Holanda tratou de defender seu projeto editorial. Ao responder, elencou os aspectos que condicionaram a publicação e afirmou que o sétimo volume "não pretende ser senão uma síntese predominantemente da política interna do referido período" e, no que tocava ao que Reis tratou - a "omissão total de referência ao ter provocado a Amazônia o ‘movimento migratório nordestino"” e "no campo das relações internacionais, a nossa participação com o monopólio da borracha" -, Sérgio Buarque respondeu que o assunto “está às páginas 248-249. São ao todo", continuava o organizador da coleção, "78 linhas, e linhas de mais de 70 espaços, o que não é pouco a meu ver. E se v. ainda achar pouco repare no final, onde está dito: 'Seu apogeu e colapso | da borracha | não pertencem ao Brasil monárquico"'21. Por fim, toda a justificativa de Sérgio Buarque recaía na possibilidade de os assuntos serem retomados e contemplados no Tomo sobre o período republicano.

A longa discussão e os demais motivos, bem como seus respectivos embasamentos presentes na correspondência, demonstram os embates no interior da coleção.

As escolhas dos títulos publicados nas coleções, sua organização e privilégio de temáticas revelam, sem dúvida, aproximações e disputas no interior das comissões de ambos os projetos editoriais, bem como dentre seus colaboradores.

Mas havia também aproximações, senão entre os projetos editoriais, ao menos entre seus organizadores. É interessante observar, por exemplo, o cruzamento editorial das trajetórias de Américo Jacobina Lacombe à frente da Brasiliana e de Sérgio Buarque de Holanda quando este coordenava a coleção HGCB e atuava como professor catedrático da USP na cadeira de História da Civilização Brasileira, conquistada no

\footnotetext{
${ }^{21}$ A carta se encontra em: Série: Correspondência. Subsérie: Ativa. 230 - Carta de SBH, a Artur Cezar Ferreira Reis, respondendo a comentários feitos aos volumes $6^{\circ}$ e $7^{\circ}$ da Coleção História Geral. s.l.d. s.as. 3p. (c/anot.ms.) Ca 8 P5. Fundo Sérgio Buarque de Holanda (SBH). Arquivo Central da Universidade Estadual de Campinas (Siarq-UNICAMP).
} 
concurso para provimento da cátedra, ocorrido em novembro de 1958, com a defesa da tese Visão do Paraíso: os motivos edênicos no descobrimento e colonização do Brasil ${ }^{22}$. O cruzamento dos caminhos de Lacombe e Holanda se deu, justamente, porque a tese deste último ganhou uma segunda edição como o volume 333 da coleção Brasiliana, no momento de retomada de seu crescimento no mercado editorial ${ }^{23}$.

Porém, as coleções organizadas por Lacombe e Sérgio Buarque eram bem distintas. Diferentemente da Brasiliana, a HGCB se constituiu somente de trabalhos inéditos. Seus autores, ainda que muitas vezes ligados a órgãos de incentivo à cultura, governamentais, ou não, possuíam, em sua maioria, vínculos com instituições de ensino superior. Estas, nas quais os colaboradores desenvolviam pesquisas no âmbito de suas especialidades, poderiam ser nacionais ou estrangeiras.

Outra característica distintiva era que, com exceção do sétimo volume da série, todo escrito por Sérgio Buarque, cada obra da HGCB contou com inúmeros colaboradores. Apesar de simultaneamente abarcar um grande número de colaborações de autores sem vínculo institucional, nos capítulos da coleção há uma maciça presença da USP. O que se podia considerar previsível, visto que, ao iniciar as publicações, em 1960, Sérgio Buarque de Holanda havia sido recém-empossado na cátedra de História da Civilização Brasileira da referida instituição e, portanto, era plausível supor que preferisse dar lugar a estas colaborações para tecer redes de sociabilidades ${ }^{24}$ neste novo espaço que passara a integrar no final da década de 50.

\footnotetext{
${ }^{22}$ Em 1959, ano seguinte à defesa da tese para provimento da cátedra da USP, Sérgio Buarque de Holanda teve o texto Visão do Paraíso publicado como o volume de número 107 da coleção Documentos Brasileiros da editora José Olympio. Ver: NICODEMO, 2008.

${ }^{23}$ Convém salientar, no entanto, que o cruzamento, por assim dizer, editorial das trajetórias entre Américo Jacobina Lacombe e Sérgio Buarque de Holanda já havia ocorrido no próprio interior da coleção HGCB, sob a coordenação deste último, pois Lacombe teve três capítulos publicados no Tomo I (A Época Colonial), a saber, A Igreja no Brasil Colonial, A conjuração no Rio de Janeiro e A cultura jurídica. Contudo, provavelmente devido às disputas editoriais, sua autoria só foi referenciada nos textos como "Diretor da Casa de Rui Barbosa, Ministério da Educação", sem mencionar que coordenava a Brasiliana, por mais notório que fosse tal fato.

${ }^{24}$ Termo compreendido aqui como "espaço de constituição de uma rede organizacional (que pode ser mais ou menos formal/institucional) e como um microcosmo das relações afetivas (de aproximação e/ou de rejeição)" (GOMES, 2004, p. 52-3).
} 
Assim, enquanto a Brasiliana, na fase coordenada por Américo Jacobina Lacombe, abarcava uma quantidade de autores que correspondiam a um tipo de intelectual erudito e polígrafo, a HGCB, apesar de contar com autores sem vínculo institucional declarado, teve, na maior parte de seus volumes, a participação de colaboradores vinculados à História que se produzia no espaço acadêmico, de instituições nacionais ou estrangeiras. E, apesar de a coleção Brasiliana, na fase coordenada por Américo Jacobina Lacombe, privilegiar autorias associadas a instituições diversas, e a HGCB, sob a direção de Buarque de Holanda, contar com presença significativa de autores oriundos da USP, ambas se constituíram como espaços de debates e disputas intelectuais no período entre 1956 e 1972, que, no interior do que se pode definir como campo da cultura letrada, foram paradigmáticas do processo de especialização institucional da História no Brasil.

Com propostas diferentes, os referidos projetos editoriais disputaram espaço no campo intelectual, o que evidencia, entre outras questões, conflitos em curso no processo de institucionalização das Ciências Sociais e Humanas no Brasil. Em carta a Américo Jacobina Lacombe, datada de 28 de outubro de 1957, Rubem Lima, então diretor de produção da Companhia Editora Nacional, refere-se a uma nova coleção de que ele tinha ouvido falar e que, ao que tudo indicava, estava sendo organizada sob a direção de Sérgio Buarque de Holanda. Escreve ele:

Aproveito a oportunidade para perguntar-lhe se teve ou tem conhecimento de uma História da Civilização Brasileira a ser editada pela Difusão Européia do Livro, sob orientação do Sergio Buarque de Holanda. Vi com o Dr. Aroldo de Azevedo uma carta circular da editora, dando o plano geral da obra e a relação dos colaboradores. Ao que parece tratase de trabalho relativamente suscinto [sic] (pela quantidade de laudas de original exigida) e de remuneração desvantajosa para os autores ( $\$ 225,00$ por página datilografada e cessão definitiva de direitos autorais). Em todo caso gostaria que o senhor nos informasse se teve oportunidade de ler essa carta-circular e nos desse sua opinião a respeito. Talvez fosse interessante tratarmos de divulgar imediatamente o plano e relação de colaboradores da Grande História do Brasil que o sr está preparando 25.

\footnotetext{
${ }^{25}$ Arquivo Américo Jacobina Lacombe. Fundação Casa de Rui Barbosa. Pasta Correspondência. Direção da Brasiliana.
} 
Como se sabe, a coleção a que se refere Rubem Lima não só foi organizada e publicada, como também se tornou um dos mais bem-sucedidos projetos editoriais já elaborados no Brasil ${ }^{26}$. Atentar para todos esses aspectos da Brasiliana e da HGCB permite, como se pretendeu mostrar neste texto, "dissipar um pouco da obscuridade que envolve a história dos livros" (DARNTON, 1996, p. 13) e compreender melhor algumas contingências dos debates intelectuais, em curso na sociedade brasileira da segunda metade do século $X X$, sob a perspectiva relacional entre "a historicidade dos textos e a textualidade da história" (GREENBLATT, 1991, p. 251), que permeava as coleções aqui contempladas.

\section{Referências}

ARQUIVOS: Américo Jacobina Lacombe. Fundação Casa de Rui Barbosa \& Fundo Sérgio Buarque de Holanda. Arquivo Central da Universidade Estadual de Campinas.

ARRUDA, Maria Arminda. A modernidade possível: cientistas e ciências sociais em Minas Gerais. In: MICELI, Sérgio (Org.). História das ciências sociais no Brasil. São Paulo: Editora Revista dos Tribunais, 1989. p. 287-303.

CARVALHO, José Murilo. Prefácio. In: VILAS BOAS, Glaucia. A vocação das ciências sociais no Brasil. Rio de Janeiro: Biblioteca Nacional, 2007.

CEZAR, Temístocles. Escrita da história e tempo presente na historiografia brasileira. In: DUTRA, Eliana de Freitas (Org.). O Brasil em dois tempos. Belo Horizonte: Autêntica, 2013 (prelo).

\footnotetext{
${ }^{26}$ A falta de acesso a esta carta de Rubem Lima levou Thiago Lima Nicodemo a afirmar que "No ano seguinte à defesa da tese de cátedra, Sérgio Buarque de Holanda foi convidado por Jean-Paul Monteil, então diretor da Editora Difusão Europeia do Livro, para dar concretude à ideia de realizar no campo da história do Brasil uma coleção semelhante às que o mesmo editor havia recentemente traduzido e publicado no país: História Geral das Civilizações, dirigida por Maurice Crouzet, e História Geral das Ciências, dirigida por René Taton." NICODEMO, 2004, p. 5. Contudo, como a missiva de Lima a Lacombe data de 28 de outubro de 1957 e o concurso para provimento da cátedra da USP ocorreu em novembro de 1958, se o convite de Monteil a Buarque de Holanda para coordenar os trabalhos da coleção HGCB se concretizou apenas "no ano seguinte à defesa da tese", como escreveu Nicodemo, este contato editorial já estava estabelecido antes da aprovação do autor de Visão do Paraíso no concurso da USP. O contato não se deu no ano seguinte à defesa da tese (1959), mas, no mínimo, um ano antes (1957).
} 
CHARTIER, Roger. A ordem dos livros: leitores, autores e bibliotecas na Europa entre os séculos XIV e XVIII. Brasília: Ed.UnB, 1994.

CROUZET, Maurice (Dir.). História Geral das Civilizações. São Paulo: Difel, 1955-1958.

DARNTON, Robert. O Iluminismo como negócio: história da publicação da “Enciclopédia”, 1775-1800. São Paulo: Companhia das Letras, 1996.

DUTRA, Eliana Regina de Freitas. A nação nos livros: a biblioteca ideal na coleção Brasiliana. In: ; MOLLIER, Jean-Yves. Política, nação e edição. O lugar dos impressos na construção da vida política. Brasil, Europa e Américas nos séculos XVIII-XX. São Paulo, Annablume, 2006. p. 299-315.

FAUSTO, Boris (entrevista). Organizando a História Geral da Civilização Brasileira. In: Estudos Históricos. Rio de Janeiro: CPDOC-FGV, v. 1, n. 1, jan./jun. 1988. p. 162-166.

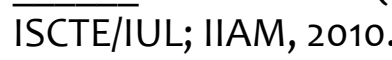

. Boris Fausto (depoimento, 2009). Rio de Janeiro, CPDOC/FGV; LAU/IFCS/UFRJ; FERREIRA, Marieta de Moraes. O ensino de História na Faculdade Nacional de Filosofia do Brasil. Manguinhos - In: História, Ciência e Saúde. Rio de Janeiro: Fiocruz, v. 19, n. 2, p. abr./jun. 2012. p. 611-636.

FRANZINI, Fábio. Interpretações do Brasil, marxismo e coleções brasilianas: quando a ausência diz muito (1931-1959). Disponível em:

<WWW.snh2011.anpuh.org/resources/anais/14/1300846039_ARQUIVO_Fabio_Franzini_Anp uh.pdf>. Acesso em: jan. 2012.

GALLAGHER, Catherine; GREENBLATT, Stephen. A prática do novo historicismo. Bauru: Edusc, 2005.

GOMES, Angela de Castro. Em família: a correspondência entre Oliveira Lima e Gilberto Freyre. In: . (Org.). Escrita de si, escrita da história. Rio de Janeiro: FGV, 2004.

. (Org.). Leituras críticas sobre Boris Fausto. Belo Horizonte: Ed.UFMG, 2008.

GREENBLATT, Stephen. O novo historicismo: ressonância e encantamento. In: Estudos Históricos. Rio de Janeiro: CPDOC-FGV, v. 4, n. 8, jul./dez. 1991. p. 244-261.

HEINICH, Nathalie. A sociologia da arte. Bauru: EDUSC, 2008. 
HOLANDA, Sérgio Buarque de (Org.). In: História Geral da Civilização Brasileira (t. I). Do descobrimento à expansão territorial (v. 1). São Paulo: Difel, 1960.

HOLANDA, Maria Amélia Buarque de Holanda. Apontamentos para a cronologia de Sérgio, 2002. Disponível em: <www.unicamp.br/siarq/sbh/biografia.html>. Acesso em: 18 fev. 2013.

LE GOFF, Jacques. História e memória. Campinas: Ed.Unicamp, 1992.

LOURENÇO, Eliane. História Nova do Brasil: revisitando uma obra polêmica. In: Revista Brasileira de História. São Paulo, v. 28, n. 56, jul./dez. 2008. p. 385-486.

MAGALHÃES, Rejane. Américo Jacobina Lacombe. Cronologia da vida e da obra. In: LUSTOSA, Isabel. Lacombe narrador (Coleção Papéis avulsos, n. 24). Rio de Janeiro: Fundação Casa de Rui Barbosa, 1996.

MICELI, Sérgio (Org.). História das ciências sociais no Brasil (v. 1). São Paulo: Vértice, 1989.

NICODEMO, Thiago Lima. A herança colonial: Sérgio Buarque de Holanda e a História Geral da Civilização Brasileira. In: I SEMINÁRIO BRASILEIRO SOBRE O LIVRO E A HISTÓRIA EDITORIAL, 2004. Rio de Janeiro. Anais. Disponível em:

<www.livroehistoriaeditorial.pro.br/pdf/thiagolimanicodemo.pdf >. Acesso em: 18 fev. 2013.

. Urdidura do vivido: Visão do Paraíso e a obra de Sérgio Buarque de Holanda nos anos 1950. São Paulo: Ed. USP, 2008.

NOGUEIRA, Arlinda Rocha et. al. (Orgs.). Sérgio Buarque de Holanda: vida e obra. São Paulo: Secretaria de Estado da Cultura / Arquivo do Estado / Universidade de São Paulo / Instituto de Estudos Brasileiros, 1988.

NOVAIS, Fernando (Org.). HOLANDA, Sérgio Buarque de. Capítulos de História do Império. São Paulo: Companhia das Letras, 2010.

OLIVERO, Isabelle. L'invention de la collection: de la diffusion de la littérature et des savoirs à la formation du citoyen au XIXe siècle. Paris: IMEC, 1999.

ROIZ, Diogo da Silva. A institucionalização do ensino de geografia e história na Faculdade de Filosofia, Ciências e Letras da Universidade de São Paulo entre 1934 e 1956. In: Agora. Santa Cruz do Sul: UNISC, v. 13, n. 1, jan./jun. 2007. p. 65-104.

SÃO PAULO. Decreto ${ }^{\circ} 52.326$ de 16.12.1969. Aprovação do Estatuto da Universidade de São Paulo - USP. Disponível em: <www.jusbrasil.com.br/legislacao/223638/decreto-5232669-sao-paulo-sp>. Acesso em: 18 fev. 2013. 
SENNA, Homero. Vida e obra de Américo Jacobina Lacombe. In: Américo Jacobina
Lacombe (Coleção Papéis Avulsos, n. 28). Rio de Janeiro: Fundação Casa de Rui Barbosa, 1996.

TATON, René (Dir.). História Geral das Ciências. São Paulo: Difel, 1959-1967.

TOLEDO, Maria Rita. A Companhia Editora Nacional e a política de editar coleções: entre a formação do leitor e o mercado de livros. In: ABREU, Marcia; BRAGANÇA, Aníbal (Orgs.). Impresso no Brasil: dois séculos de livros brasileiros. São Paulo: Unesp/ Rio de Janeiro: Biblioteca Nacional, 2010, p. 139-156.

VILAS BOAS, Glaucia. A vocação das ciências sociais no Brasil. Rio de Janeiro: Biblioteca Nacional, 2007.

VILHENA, Luis Rodolfo. Projeto e missão: o movimento folclórico brasileiro, 1947-1964. Rio de Janeiro: FGV / Funarte, 1997. 